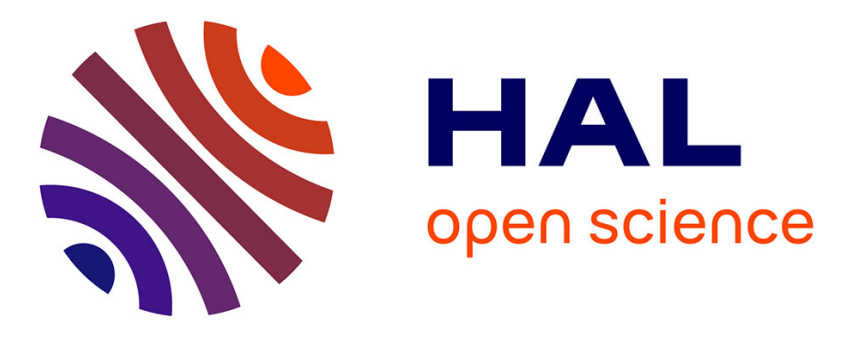

\title{
Voriconazole drastically increases exposure to oral oxycodone
}

\author{
Nora M. Hagelberg, Tuija H. Nieminen, Teijo I. Saari, Mikko Neuvonen, \\ Pertti J. Neuvonen, Kari Laine, Klaus T. Olkkola
}

\section{- To cite this version:}

Nora M. Hagelberg, Tuija H. Nieminen, Teijo I. Saari, Mikko Neuvonen, Pertti J. Neuvonen, et al.. Voriconazole drastically increases exposure to oral oxycodone. European Journal of Clinical Pharmacology, 2008, 65 (3), pp.263-271. 10.1007/s00228-008-0568-5 . hal-00477928

\section{HAL Id: hal-00477928 \\ https://hal.science/hal-00477928}

Submitted on 30 Apr 2010

HAL is a multi-disciplinary open access archive for the deposit and dissemination of scientific research documents, whether they are published or not. The documents may come from teaching and research institutions in France or abroad, or from public or private research centers.
L'archive ouverte pluridisciplinaire HAL, est destinée au dépôt et à la diffusion de documents scientifiques de niveau recherche, publiés ou non, émanant des établissements d'enseignement et de recherche français ou étrangers, des laboratoires publics ou privés. 


\title{
Voriconazole drastically increases exposure to oral oxycodone
}

\author{
Nora M. Hagelberg • Tuija H. Nieminen • \\ Teijo I. Saari • Mikko Neuvonen • Pertti J. Neuvonen • \\ Kari Laine $\cdot$ Klaus T. Olkkola
}

Received: 27 June 2008 / Accepted: 8 September 2008 /Published online: 3 October 2008

(C) Springer-Verlag 2008

\begin{abstract}
Objective We investigated the effect of voriconazole on the pharmacokinetics and pharmacodynamics of oxycodone.

Methods Twelve healthy subjects ingested either voriconazole or placebo for 4 days in a randomized, cross-over study. On day 3 , they ingested $10 \mathrm{mg}$ oxycodone. Timed plasma samples were collected for the measurement of oxycodone, noroxycodone, oxymorphone, noroxymorphone and voriconazole up to $48 \mathrm{~h}$, and pharmacodynamic effects were recorded.

Results When voriconazole was taken at the same time as oxycodone, the mean area under the plasma concentrationtime curve $\left(\mathrm{AUC}_{0-\infty}\right)$ of oxycodone increased 3.6-fold (range 2.7- to 5.6-fold), peak plasma concentration 1.7-fold and elimination half-life 2.0 -fold $(p<0.001)$ when compared to placebo. The $\mathrm{AUC}_{0-\infty}$ ratio of noroxycodone to oxycodone was decreased by $92 \%(p<0.001)$, and that of oxymorphone increased by $108 \%(p<0.01)$. Pharmacodynamic effects of oxycodone were modestly increased by voriconazole.
\end{abstract}

\footnotetext{
N. M. Hagelberg • T. H. Nieminen • T. I. Saari •

K. T. Olkkola $(\bowtie)$

Department of Anaesthesiology, Intensive Care,

Emergency Care and Pain Medicine, Turku University Hospital, P.O. Box 52 (Kiinamyllynkatu 4-8), FI-20521 Turku, Finland

e-mail: klaus.olkkola@utu.fi
}

M. Neuvonen · P. J. Neuvonen

Department of Clinical Pharmacology, University of Helsinki, P.O. Box 705, FI-00029 Helsinki, Finland

\section{K. Laine}

Department of Pharmacology, Drug Development \& Therapeutics, University of Turku,

Itäinen pitkäkatu 4,

FI-20520 Turku, Finland
Conclusions Voriconazole inhibits the CYP3A-mediated Ndemethylation of oxycodone, drastically increasing exposure to oral oxycodone. Clinically, lower doses of oxycodone may be needed during voriconazole treatment to avoid opioidrelated adverse effects especially after repeated dosing.

Keywords Oxycodone - Voriconazole - Cytochrome P450 . CYP2D6 C CYP3A $\cdot$ Pharmacokinetics

\section{Introduction}

Oxycodone is a semi-synthetic $\mu$-opioid receptor agonist widely used in the treatment of acute and chronic pain. The bioavailability of oxycodone is over $60 \%$ [1]. Oxycodone undergoes oxidative metabolism mainly in the liver by cytochrome P450 (CYP) 3A and 2D6 enzymes [2]. About $10 \%$ of the parent compound is excreted unchanged or as direct conjugates in urine. The majority of oxycodone is $\mathrm{N}$ demethylated to noroxycodone predominantly via CYP3A, and less than $10 \%$ is O-demethylated to oxymorphone via CYP2D6. These metabolites undergo further oxidation through CYP3A to form noroxymorphone $[2,3]$.

Voriconazole is an antifungal agent clinically used in the treatment of disseminated fungal infections. The bioavailability of oral voriconazole is over $90 \%$ and its pharmacokinetics is nonlinear [4]. Voriconazole undergoes extensive hepatic oxidative metabolism via CYP2C19 and CYP3A, and possibly CYP2C9 $[5,6]$. Less than $2 \%$ of voriconazole dose is excreted unchanged in urine. Voriconazole inhibits the enzyme activities of CYP3A, CYP2C19 and CYP2C9 but not CYP2D6 [7, 8].

Previous studies indicate that changes in CYP3A and CYP2D6 enzyme activities may impair the metabolism of oxycodone. Inhibition of CYP2D6 activity with quinidine 
increases noroxycodone concentration and blocks the formation of oxymorphone, but does not influence oxycodone concentration [9]. Competition of CYP2D6 and CYP3A enzyme activities with a single dose of tramadol has no effect on the clearance of oxycodone whereas indirect evidence suggests that ketoconazole influences the pharmacokinetics of oxycodone [10, 11]. Considering that the major metabolic pathway occurs via CYP3A enzymes, changes in CYP3A activity may be more relevant in terms of the clinical effects of oxycodone. A clinical case report suggests that the analgesic effect of oxycodone is diminished by concomitant treatment with rifampicin [12]. The aim of the present study was to investigate the effects of the CYP3A, CYP2C9 and CYP2C19 enzyme inhibitor voriconazole on the pharmacokinetics and pharmacodynamics of oxycodone in healthy subjects.

\section{Materials and methods}

\section{Subjects}

Twelve healthy non-smoking subjects, including six women and six men (age range 19-25 years and weight range 50$95 \mathrm{~kg}$ ), participated in the study after giving written informed consent. The general health of the subjects was good as assessed by their medical history, clinical examination, routine laboratory tests and an ECG. The risk for participants of developing aberrant opioid-related behaviour was estimated low as evaluated by the Finnish translation of the Abuse Questions [13]. Urine toxicology screens were negative. The subjects consented to abstain from any medication for 2 weeks and any products with known effects on CYP enzyme activity for 4 weeks prior to the study. Female subjects used safe non-hormonal contraception during the study, as hormonal contraceptives were not allowed. The Ethics Committee of the Hospital District of Southwest Finland, Finland, and the National Agency of Medicines, Finland, approved the study protocol. The study was conducted according to the revised Declaration of Helsinki.

\section{Study outline}

The study was conducted in a placebo-controlled, randomized, cross-over design with two phases. The wash-out interval was 4 weeks. The subjects took either voriconazole (voriconazole phase) or placebo (control phase) in a randomized order for 4 days. On day 3, the subjects received a single dose of oxycodone. Blood samples were collected immediately before, and at $0.5,1,1.5,2,3,4,5$, $6,8,10,12,24$ and $48 \mathrm{~h}$ after oxycodone administration. The behavioural and analgesic effects were evaluated prior to and at $1,2,3,4,5,6,8,10$ and $12 \mathrm{~h}$ after the administration of oxycodone, except for heat-pain analgesia which was assessed prior to and $1 \mathrm{~h}$ after oxycodone dosing.

Study drug administration

Dosing of voriconazole (Vfend $200 \mathrm{mg}$ tablet; Pfizer, Sandwich, UK) was as follows: $400 \mathrm{mg}$ at 7 P.M. on day $1,400 \mathrm{mg}$ at 7 A.M. and $200 \mathrm{mg}$ at 7 P.M. on day 2, and $200 \mathrm{mg}$ at 7 A.M. and 7 P.M. on days 3 and 4. Voriconazole and placebo were self-administered by the subjects except for day 3 when they were administered by the investigators. Adherence with the dosing schedule was assessed using mobile phone text messages. The subjects sent a mobile phone text message to one of the investigators after taking each dose. If no text message was received within 15$20 \mathrm{~min}$ after scheduled dosing time, the investigator contacted the subject by phone and reminded him/her to take the dose. On day $3,1 \mathrm{~h}$ after voriconazole or placebo dosing, an oral dose of oxycodone hydrochloride $10 \mathrm{mg}$ (Oxynorm; Mundipharma, Bard Pharmaceuticals, Cambridge, UK) was administered in the study facility with $150 \mathrm{ml}$ of water. During both phases, the subject fasted overnight before the administration of oxycodone and continued fasting until a standardized lunch was served $4 \mathrm{~h}$ after oxycodone dosing.

\section{Blood sampling and drug analysis}

In the study facility, a forearm vein was cannulated for collecting timed blood samples $(10 \mathrm{ml})$ into ethylenediaminetetraaceticacid containing tubes. Plasma was separated within $30 \mathrm{~min}$ of sampling and stored at $-70^{\circ} \mathrm{C}$ until analysis.

Plasma concentration of voriconazole was determined by high-performance liquid chromatography [14, 15]. The lower limit of quantification (LLQ) was $20 \mathrm{ng} / \mathrm{ml}$. The interday coefficients of variation (CV) were 9.7 and $1.6 \%$ at 1,031 and $9,654 \mathrm{ng} / \mathrm{ml}$ respectively $(n=6)$.

Plasma concentrations of oxycodone, noroxycodone, oxymorphone and noroxymorphone were analysed with the liquid chromatography tandem mass spectrometric method as previously described [16]. The LLQ was $0.1 \mathrm{ng} / \mathrm{ml}$ for oxycodone and oxymorphone and $0.25 \mathrm{ng} /$ $\mathrm{ml}$ for noroxycodone and noroxymorphone. The CV at 0.1 , 4.9 and $99 \mathrm{ng} / \mathrm{ml}$ was $7.0,1.8$ and $2.0 \%(n=6)$ respectively for oxycodone, and less than $15 \%$ for the rest of the analytes at relevant plasma concentrations.

Genotyping for CYP2D6 was performed using a twostep multiplex primer extension method [17]. The method allows the detection of 11 of the most relevant polymorphic positions, the assessment of whole-gene deletion and duplication and the allele composition of gene duplication. 
Pharmacokinetic measurements

Pharmacokinetic variables of oxycodone, noroxycodone, oxymorphone and noroxypmorphone were determined using the WinNonlin pharmacokinetic program (version 4.1; Pharsight, Mountain View, California). The peak plasma concentration $\left(\mathrm{C}_{\max }\right)$ and time to maximum concentration $\left(t_{\max }\right)$ were observed directly from the data. The area under the plasma concentration-time curve with extrapolation to infinity $\left(\mathrm{AUC}_{0-\infty}\right)$ was calculated by the trapezoidal rule. The linear trapezoidal rule was used for successive increasing concentration values, and the logarithmic trapezoidal rule for decreasing concentration values. Individual terminal log-linear phases of plasma concentration-time curves were identified visually, and the elimination rate constant $\left(\mathrm{K}_{\mathrm{e}}\right)$ was determined by regression analysis. The elimination half-life $\left(\mathrm{t}_{1 / 2}\right)$ was calculated using the following equation: $t_{1 / 2}=\ln 2 / \mathrm{K}_{\mathrm{e}}$. The apparent clearance $(\mathrm{CL} / \mathrm{F})$ and apparent volume of distribution during elimination $\left(\mathrm{V}_{\mathrm{z}} / \mathrm{F}\right)$ were calculated. Metabolite-toparent drug $\mathrm{AUC}$ ratios $\left(\mathrm{AUC}_{\mathrm{m}} / \mathrm{AUC}_{\mathrm{p}}\right)$ were calculated to compare the relative abundance of each metabolite.

\section{Pharmacodynamic measurements}

Behavioural effects Behavioural effects of oxycodone were assessed with 100-mm visual analogue scales for the following items: alert/drowsy, good performance/poor performance, no drug effect/strong drug effect, unpleasant feeling/ pleasant feeling, no nausea/extreme nausea or vomiting [18]. Central co-ordination of extraocular muscles was evaluated using Maddox wing test, which measures horizontal heterophoria in diopters [19]. Central processing of sensory information was assessed with the digit symbol substitution test (DSST) [20]. The pupil size was measured with Cogan's pupillometry [21]. In addition, any adverse events spontaneously reported by the subjects were recorded.

Analgesic effects Cutaneous heat-pain threshold was determined using a feedback-controlled contact thermode (TSA-2; Medoc, Rehovot, Israel). This device delivers three heat-pain stimuli of slowly increasing $\left(1^{\circ} \mathrm{C} / \mathrm{s}\right)$ temperature to the right volar forearm. The size of the thermode was $30 \times 30 \mathrm{~mm}$. Heat increased linearly from a baseline temperature of $35^{\circ} \mathrm{C}$ until the subject reported the first sensation of pain by pressing a button. This temperature was recorded, and the temperature returned to baseline. The interval between the stimuli was approximately $30 \mathrm{~s}$. To avoid sensitisation, testing site on the skin differed slightly. Heat-pain threshold was defined as the mean of the three temperature measurements.

Cold pressor test [22] was used to assess cold-pain sensitivity. The subject immersed his or her left hand into ice water of $0.5-2^{\circ} \mathrm{C}$ up to the wrist for $1 \mathrm{~min}$. The latency in seconds from the immersion to the first sensation of pain
Fig. 1 Mean plasma concentrations $( \pm \mathrm{SD})$ of oxycodone, noroxycodone, oxymorphone and noroxymorphone after an oral dose of $10 \mathrm{mg}$ of oxycodone hydrochloride during the placebo phase (open circles, control) or voriconazole phase (closed circles) in 12 healthy subjects. The inset depicts the same data on a semilogarithmic scale. The dose of voriconazole was $400 \mathrm{mg}$ twice daily on the first day followed by five further doses of $200 \mathrm{mg}$ of voriconazole at 12 -h intervals
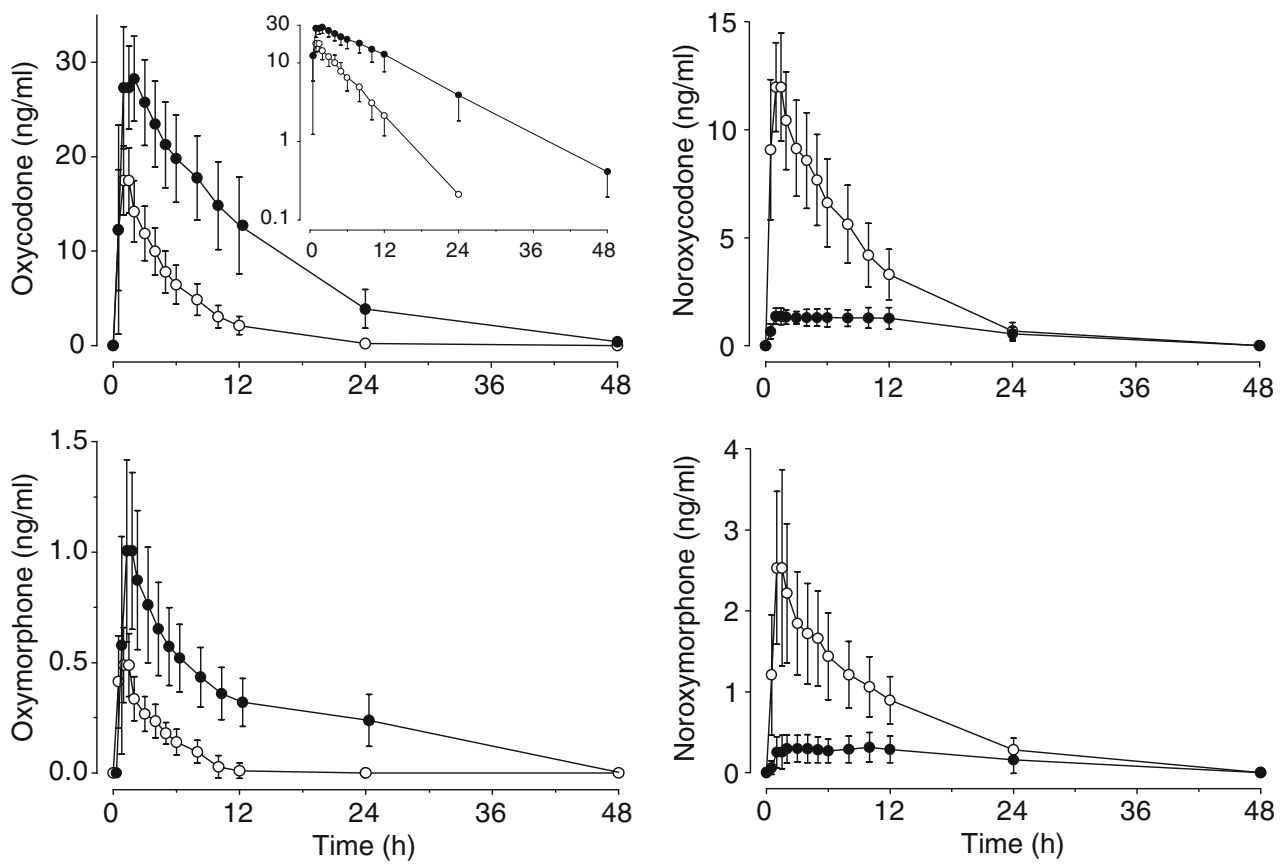

o Oxycodone + placebo

- Oxycodone+ voriconazole 
was defined as the cold-pain threshold. During the immersion, the subject reported the intensity of cold pain at $30 \mathrm{~s}$ (CPI30) and $60 \mathrm{~s}$ (CPI60) using a numerical rating scale $(\mathrm{NRS}, 0=$ no pain or unpleasantness, $100=$ maximum pain or unpleasantness). If the pain became intolerable, the subject was allowed to withdraw his or her hand from the water. In such a case, the intensity and unpleasantness after withdrawal were recorded as maximum (100).
Table 1 Pharmacokinetic parameters of oxycodone and its primary and secondary oxidative metabolites after oral administration of $10 \mathrm{mg}$ of oxycodone hydrochloride following pre-treatment with placebo (control) and oral voriconazole in 12 healthy volunteers. The dose of voriconazole was $400 \mathrm{mg}$ twice daily on the first day followed by five further doses of $200 \mathrm{mg}$ of voriconazole at 12 -h intervals. Values are mean \pm standard deviation. Percent of control was calculated individually for each subject, and the mean and range of these individual values are reported

\begin{tabular}{|c|c|c|c|}
\hline Parameter & Control phase & Voriconazole phase & $95 \% \mathrm{CI}$ of difference between the phases \\
\hline \multicolumn{4}{|l|}{ Oxycodone } \\
\hline $\mathrm{C}_{\max }(\mathrm{ng} / \mathrm{ml})$ & $18.1 \pm 4.0$ & $30.5 \pm 5.1 * * *$ & 10.3 to 14.5 \\
\hline$\%$ of control (range) & 100 & $172(140-224)$ & \\
\hline $\mathrm{t}_{\max }(\mathrm{h})$ & $1.0(0.5-1.5)$ & $1.5(1.0-4.0)^{*}$ & \\
\hline $\mathrm{AUC}_{0-\infty}(\mu \mathrm{g} \mathrm{min} / \mathrm{ml})$ & $6.1 \pm 1.6$ & $21.8 \pm 6.2 * * *$ & 12.4 to 19.1 \\
\hline$\%$ of control (range) & 100 & $361(268-563)$ & \\
\hline $\mathrm{CL} / \mathrm{F}(\mathrm{l} / \mathrm{min})$ & $1.58 \pm 0.51$ & $0.46 \pm 0.20^{* * *}$ & -1.34 to -0.91 \\
\hline$\%$ of control (range) & 100 & $29(18-37)$ & \\
\hline $\mathrm{V}_{\mathrm{z}} / \mathrm{F}(\mathrm{l})$ & $474 \pm 139$ & $266 \pm 62 * * *$ & -265 to -152 \\
\hline$\%$ of control (range) & 100 & $57(44-78)$ & \\
\hline $\mathrm{t}_{1 / 2}(\mathrm{~h})$ & $3.5 \pm 0.6$ & $7.1 \pm 1.0^{* * *}$ & 3.1 to 4.1 \\
\hline$\%$ of control (range) & 100 & $203(144-246)$ & \\
\hline \multicolumn{4}{|l|}{ Noroxycodone } \\
\hline $\mathrm{C}_{\max }(\mathrm{ng} / \mathrm{ml})$ & $12.6 \pm 2.3$ & $1.6 \pm 0.5 * * *$ & -12.3 to -9.7 \\
\hline$\%$ of control (range) & 100 & $13(9-21)$ & \\
\hline $\mathrm{t}_{\max }(\mathrm{h})$ & $1.0(0.5-1.5)$ & $1.8(1.0-12.0)^{*}$ & \\
\hline $\mathrm{AUC}_{0-\infty}(\mu \mathrm{g} \min / \mathrm{ml})$ & $6.5 \pm 1.9$ & $2.1 \pm 0.9 * * *$ & -5.5 to -3.3 \\
\hline$\%$ of control (range) & 100 & $33(19-63)$ & \\
\hline $\mathrm{AUC}_{\mathrm{m}} / \mathrm{AUC}_{\mathrm{p}}$ & $1.07 \pm 0.19$ & $0.09 \pm 0.02 * * *$ & -1.09 to -0.87 \\
\hline$\%$ of control (range) & 100 & $8(7-12)$ & \\
\hline $\mathrm{t}_{1 / 2}(\mathrm{~h})$ & $5.3 \pm 1.0$ & $10.9 \pm 2.7 * * *$ & 4.1 to 7.2 \\
\hline$\%$ of control (range) & 100 & $208(141-304)$ & \\
\hline \multicolumn{4}{|l|}{ Oxymorphone } \\
\hline $\mathrm{C}_{\max }(\mathrm{ng} / \mathrm{ml})$ & $0.52 \pm 0.18$ & $1.06 \pm 0.41 * * *$ & 0.32 to 0.75 \\
\hline$\%$ of control (range) & 100 & $208(133-332)$ & \\
\hline$t_{\max }(h)$ & $1.0(0.5-1.5)$ & $1.0(0.5-1.5)$ & \\
\hline $\mathrm{AUC}_{0-\infty}(\mu \mathrm{g} \mathrm{min} / \mathrm{ml})$ & $0.150 \pm 0.046$ & $1.046 \pm 0.523 * * *$ & 0.575 to 1.217 \\
\hline$\%$ of control (range) & 100 & $727(352-1,722)$ & \\
\hline $\mathrm{AUC}_{\mathrm{m}} / \mathrm{AUC}_{\mathrm{p}}$ & $0.026 \pm 0.009$ & $0.052 \pm 0.031 * *$ & 0.010 to 0.042 \\
\hline$\%$ of control (range) & 100 & $208(90-480)$ & \\
\hline $\mathrm{t}_{1 / 2}(\mathrm{~h})$ & $3.6 \pm 0.5$ & $23.1 \pm 11.9(n=9) * *$ & 10.4 to $28.4(n=9)$ \\
\hline$\%$ of control (range) & 100 & $627(210-1,159)$ & \\
\hline \multicolumn{4}{|l|}{ Noroxymorphone } \\
\hline $\mathrm{C}_{\max }(\mathrm{ng} / \mathrm{ml})$ & $2.8 \pm 1.2$ & $0.34 \pm 0.23 * * *$ & -3.1 to -1.8 \\
\hline$\%$ of control (range) & 100 & $11(0-18)$ & \\
\hline $\mathrm{t}_{\max }(\mathrm{h})$ & $1.5(1.0-3.0)$ & $5.0(1.0-10.0)$ & \\
\hline $\mathrm{AUC}_{0-\infty}(\mu \mathrm{g} \mathrm{min} / \mathrm{ml})$ & $1.70 \pm 0.47$ & $0.86 \pm 0.76^{* * *}$ & -1.22 to -0.46 \\
\hline$\%$ of control (range) & 100 & $47(0-112)$ & \\
\hline $\mathrm{AUC}_{\mathrm{m}} / \mathrm{AUC}_{\mathrm{p}}$ & $0.299 \pm 0.121$ & $0.040 \pm 0.030 * * *$ & -0.32 to -0.20 \\
\hline$\%$ of control (range) & 100 & $12(0-28)$ & \\
\hline $\mathrm{t}_{1 / 2}(\mathrm{~h})$ & $8.9 \pm 2.4$ & $28.3 \pm 15.2(n=9) * *$ & 8.3 to 32.3 \\
\hline$\%$ of control (range) & 100 & $368(149-790)$ & \\
\hline
\end{tabular}

$C I$ Confidence interval, $C_{\max }$ maximum concentration, $t_{\max }$ time to maximum concentration, $A U C_{0-\infty}$ area under plasma concentration-time curve extrapolated to infinity, $C L / F$ apparent clearance, $V_{Z} / F$ apparent volume of distribution, $t_{1 / 2}$ terminal elimination half-life, $A U C_{m} / A U C_{p}$ metaboliteto-parent drug area under plasma concentration-time curve ratio ${ }^{*} p<0.05, * * p<0.01, * * * p<0.001$ 
The area under the response-time curve for $12 \mathrm{~h}\left(\mathrm{AUC}_{0-12}\right)$ for all pharmacodynamic variables except for the heat pain test was determined using the trapezoidal rule.

\section{Statistical analysis}

Differences in pharmacokinetic and pharmacodynamic variables between voriconazole and placebo phases were analysed using Student's $t$-test except for $t_{\max }$, which was analysed with Wilcoxon signed-ranks test. The contributions of oxycodone and voriconazole to overall variance in heat- and cold-pain thresholds and cold-pain intensity were analysed by analysis of variance. The possible association of plasma concentration of oxycodone with pharmacological effect was calculated using Pearson's product-moment correlation coefficient. Pearson's product-moment correlation coefficient was also used to investigate the possible relationship between the ratio of the $\mathrm{AUC}_{0-\infty}$ of oxycodone during voriconazole phase to $\mathrm{AUC}_{0-\infty}$ of oxycodone during the control phase and the $\mathrm{AUC}_{0-48}$ of voriconazole. All data were analysed using the statistical program SYSTAT for Windows (version 10.2; SystatSoftware, Richmond, $\mathrm{CA})$. The results are expressed as mean $\pm \mathrm{SD}$ or median (range) whenever appropriate. $P$ values $<0.05$ were considered as statistically significant.

\section{Results}

Pharmacokinetics

Oxycodone Voriconazole greatly increased plasma concentrations of the parent oxycodone. During the voriconazole phase, the mean $\mathrm{AUC}_{0-\infty}$ of oxycodone increased 3.6-fold (range 2.7- to 5.6-fold; $p<0.001$ ), the mean $\mathrm{C}_{\max }$ of oxycodone 1.7-fold (range 1.4- to 2.2-fold; $p<0.001$ ) and the mean $\mathrm{t}_{1 / 2}$ 2.0-fold (range 1.4-2.5-fold; $p<0.001$ ) compared to the placebo phase. The mean plasma concentration of oxycodone at $24 \mathrm{~h}$ in the voriconazole phase was approximately at the same level as at $8-10 \mathrm{~h}$ after placebo. Voriconazole decreased $\mathrm{CL} / \mathrm{F}$ of oxycodone by $71 \%$ and $\mathrm{V}_{\mathrm{z}} / \mathrm{F}$ by $43 \%$ (Fig. 1, Table 1 ).

Noroxycodone Voriconazole decreased the mean $\mathrm{C}_{\max }$ of noroxycodone by $87 \%(p<0.001)$ and its $\mathrm{AUC}_{0-\infty}$ by $67 \%$ $\left(p<0.001\right.$; Fig. 1, Table 1). The $\mathrm{AUC}_{\mathrm{m}} / \mathrm{AUC}_{\mathrm{p}}$ ratio was decreased by $92 \%(p<0.001$; Fig. 2 , Table 1$)$. The mean $t_{1 / 2}$ of noroxycodone was prolonged by 2.1 -fold, to 10.9 from $5.3 \mathrm{~h}(p<0.001)$.

Oxymorphone Voriconazole increased the $\mathrm{C}_{\max }$ of oxymorphone by $108 \%(p<0.001)$ and $\mathrm{AUC}_{0-\infty}$ by 7.3 -fold $(p<0.001)$, on the average (Fig. 1, Table 1). The $\mathrm{AUC}_{\mathrm{m}} /$
$\mathrm{AUC}_{\mathrm{p}}$ ratio was increased by $108 \%$ (Fig. 2, Table 1) and the mean $t_{1 / 2}$ prolonged 6.6 -fold, by $19.5 \mathrm{~h}$.

Noroxymorphone Voriconazole decreased the $\mathrm{C}_{\max }$ of noroxymorphone by $89 \%$ and the $\mathrm{AUC}_{0-\infty}$ by $53 \%$ (Fig. 1, Table 1). The $\mathrm{AUC}_{\mathrm{m}} / \mathrm{AUC}_{\mathrm{p}}$ ratio was decreased
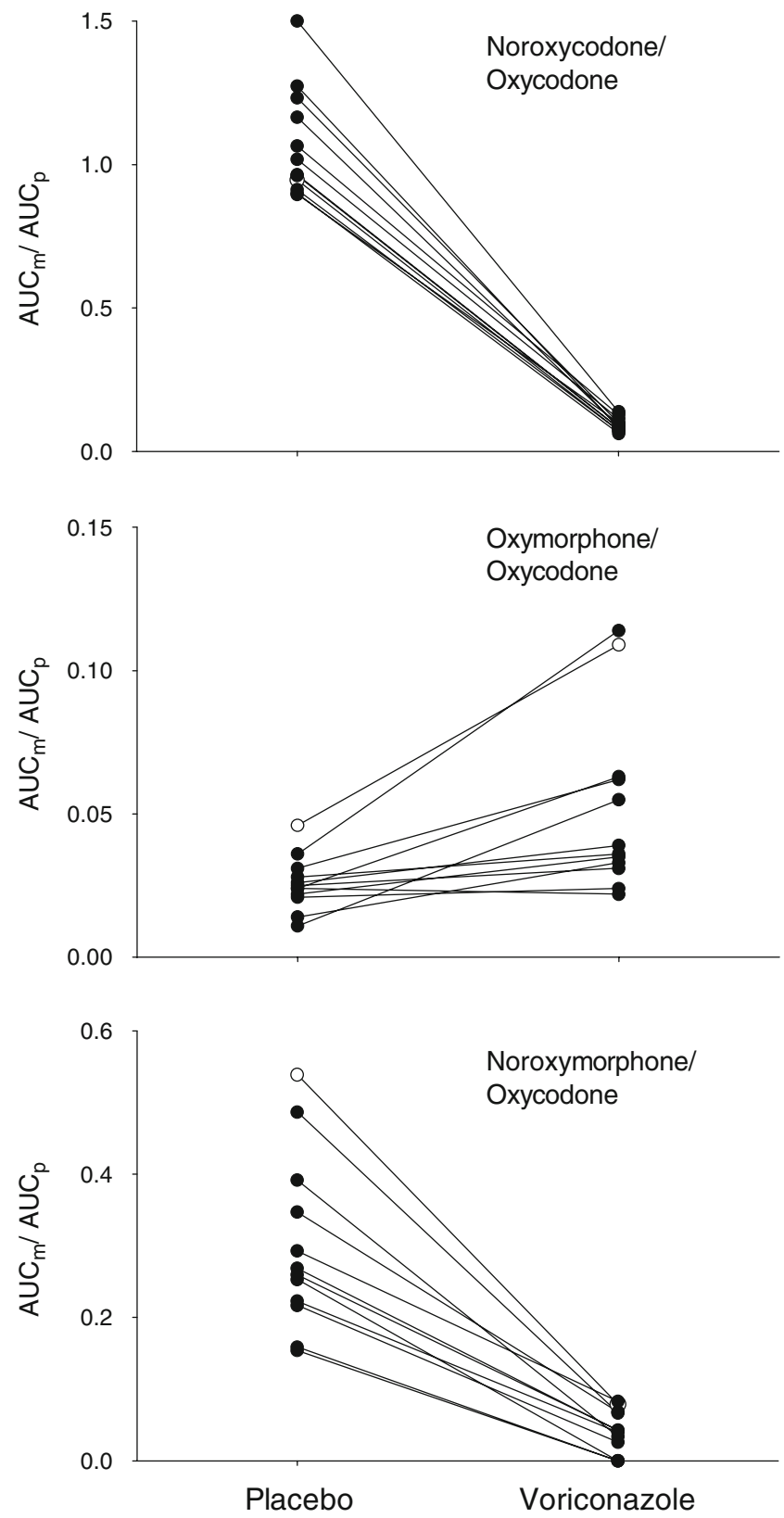

Fig. 2 Individual metabolite-to-parent drug AUC ratios $\left(\mathrm{AUC}_{\mathrm{m}} /\right.$ $\mathrm{AUC}_{\mathrm{p}}$ ) after an oral dose of $10 \mathrm{mg}$ of oxycodone hydrochloride reflecting the relative abundance of each metabolite during the control and voriconazole phases. Each circle represents one subject. The subject with ultrarapid metabolism via CYP2D6 is depicted with an open circle. The dose of voriconazole was $400 \mathrm{mg}$ twice daily on the first day followed by five further doses of $200 \mathrm{mg}$ of voriconazole at 12-h intervals 


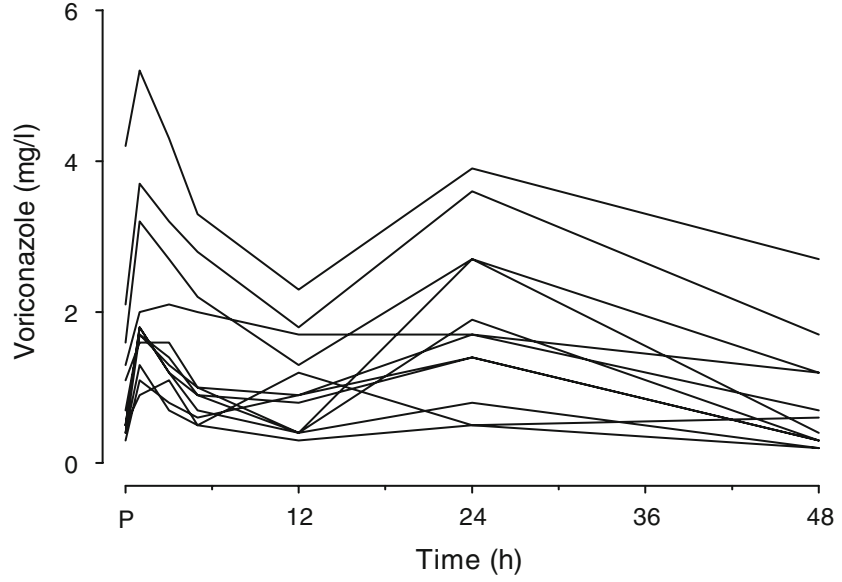

Fig. 3 Individual plasma concentrations of voriconazole in 12 healthy subjects. The dose of voriconazole was $400 \mathrm{mg}$ twice daily on the first day followed by five further doses of $200 \mathrm{mg}$ of voriconazole at 12-h intervals. $P$ refers to the time point of the last dose of voriconazole before the administration of oxycodone

by $88 \%$ (Fig. 2). The $t_{1 / 2}$ of noroxymorphone was prolonged by $19.4 \mathrm{~h}$.

Plasma voriconazole There was about a 5- to 10-fold interindividual variation in the $\mathrm{AUC}_{0-48}$ of voriconazole (Fig. 3). However, there was no significant linear correlation between the plasma concentration of voriconazole and any of the voriconazole-induced changes observed in the pharmacokinetic or pharmacodynamic parameters.
CYP2D6 genotyping Eleven subjects were classified as extensive metabolizers (EM). Five of them were homozygous for $C Y P 2 D 6^{*} 1$ allele, four had the genotype $C Y P 2 D 6^{*} 1 / * 4$, one had genotype $C Y P 2 D 6^{*} 1 / * 3$ and one had $C Y P 2 D 6^{*} 1 / * 6$. One subject was classified as an ultrarapid metabolizer (UM) having a $C Y P 2 D 6^{*} 1 / * 1 \times 2$ genotype. The subject with UM CYP2D6 genotype had approximately $50 \%$ lower values for oxycodone $\mathrm{C}_{\max }$ and $\mathrm{AUC}_{0-\infty}$ than the rest of the volunteers. This subject differed distinctly from the others also in regard to the plasma concentrations of oxymorphone and noroxymorphone (Fig. 2).

\section{Pharmacodynamics}

Behavioural effects Voriconazole increased oxycodone-induced $\mathrm{AUC}_{0-12}$ for heterophoria $(p<0.05)$ and miosis $(p<$ $0.001)$ when compared to placebo. Voriconazole also appeared to increase the perceived subjective drug effect, but the difference was not statistically significant $(p=$ 0.076). No other behavioural differences were observed (Fig. 4). There was a statistically significant linear correlation between the behavioural effects and plasma oxycodone concentration (for heterophoria $p<0.05$ and for all other variables $p<0.001)$.

Analgesic effects Oxycodone increased the heat-pain threshold $(p<0.05)$ and cold-pain threshold $(p<0.05)$, and
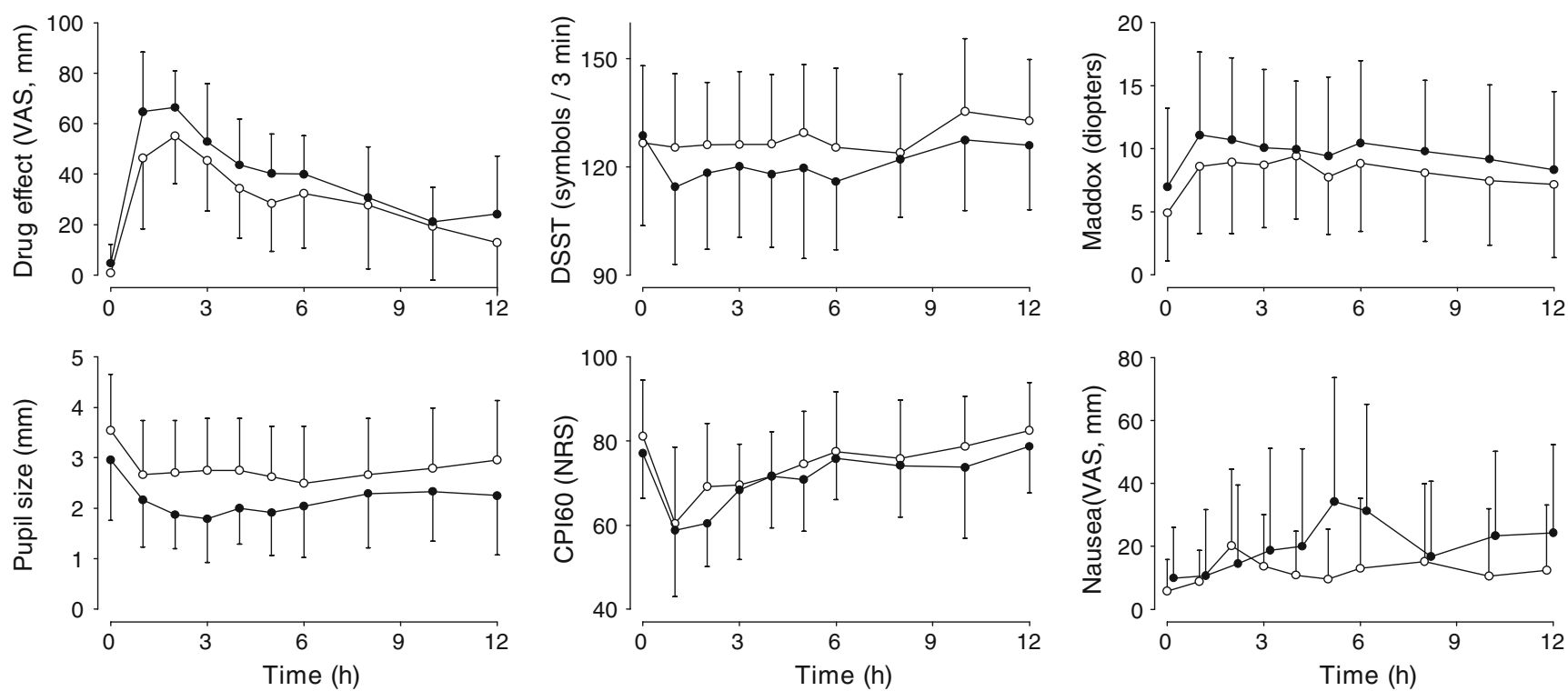

- Oxycodone + placebo

- Oxycodone + voriconazole

Fig. 4 Mean ( \pm SD) self-reported drug effect, number of digits substituted in $3 \mathrm{~min}$ (DSST), heterophoria (Maddox), pupil size, coldpain intensity at $60 \mathrm{~s}(C P I 60)$, and nausea after an oral dose of $10 \mathrm{mg}$ of oxycodone hydrochloride during the placebo phase (open circles, control) or voriconazole phase (closed circles) in 12 healthy subjects. The dose of voriconazole was $400 \mathrm{mg}$ twice daily on the first day followed by five further doses of $200 \mathrm{mg}$ of voriconazole at 12-h intervals 
decreased the mean $\mathrm{AUC}_{0-12}$ for cold-pain intensity at $60 \mathrm{~s}$ $(p<0.001)$. However, voriconazole did not alter the effect of oxycodone on any of these pharmacodynamic variables (Fig. 4). Except for heat-pain threshold, there was a statistically significant linear correlation between the analgesic effect and plasma oxycodone concentration $(p<$ $0.001)$.

Adverse events All subjects completed the study. Eight of the 12 subjects experienced adverse events on day 3 . Adverse events were headache $(n=5)$, nausea $(n=3)$, vomiting $(n=1)$, dizziness $(n=2)$, extreme fatigue $(n=1)$ and itch $(n=1)$. Three subjects received paracetamol $(1,000 \mathrm{mg})$ for headache $12 \mathrm{~h}$ after oxycodone dosing, and one received tropisetrone $2 \mathrm{mg}$ iv for nausea $5 \mathrm{~h}$ after dosing. All cases of nausea or vomiting were reported during the voriconazole phase. Number of reports of headache did not differ between voriconazole and control phases.

\section{Discussion}

This study indicates that voriconazole profoundly inhibited the CYP3A-catalyzed N-demethylation of oxycodone in all subjects, detected as an average 3.6-fold increase in oxycodone $\mathrm{AUC}_{0-\infty}$ and $92 \%$ decrease in the $\mathrm{AUC}_{\mathrm{m}} / \mathrm{AUC}_{\mathrm{p}}$ ratio of noroxycodone. Alhough voriconazole enhanced some of the behavioural effects of a single oral dose of oxycodone, the analgesic effects of oxycodone were not significantly affected by voriconazole. It is plausible to assume that the observed pharmacokinetic changes are due to a marked decrease in the first-pass metabolism and plasma clearance of oxycodone because both the $\mathrm{C}_{\max }$, $\mathrm{AUC}_{0-\infty}$ and $\mathrm{t}_{1 / 2}$ of oxycodone were greatly increased by voriconazole, and these changes were accompanied by drastic changes in the metabolite-to-oxycodone ratios.

Previous human studies have shown that voriconazole alters the pharmacokinetics of several drugs metabolized by CYP3A, including oral hypnotics [23-25] and opioids [2628]. Voriconazole decreases the clearance of alfentanil by $83 \%$ [26] and that of fentanyl by $23 \%$ [27], and increases the $\mathrm{AUC}_{0-24}$ of R-methadone by $47 \%$ [28]. In the present study, following oral administration of oxycodone the plasma clearance could not be calculated, but voriconazole increased the exposure to oxycodone by 3.6-fold as judged by the mean value for oxycodone $\mathrm{AUC}_{0-\infty}$. While voriconazole strongly decreased the plasma concentration of noroxycodone, the concentration of oxymorphone was substantially (on average 7.3-fold) increased. As studies in human liver microsomes suggest that voriconazole does not affect CYP2D6 activity [6, 7], the increase in plasma concentration of oxymorphone probably reflects a compensatory reaction to the inhibition of CYP3A. The compensatory increase in the CYP2D6-mediated route of metabolism (O-demethylation) could not replace the CYP3A-mediated N-demethylation of oxycodone, which resulted in a markedly delayed elimination of oxycodone. Interestingly, voriconazole did not increase oxycodone concentrations to the same extent as those of midazolam. This is most likely due to the differences in the bioavailability of oxycodone and midazolam. Because oxycodone has a higher bioavailability than midazolam, it is somewhat less prone to the effects of other drugs affecting CYP enzymes during absorption and during first-pass metabolism $[29,30]$.

In the present study both voriconazole and oxycodone were administrated orally. The extent of interaction might have been of different magnitude had either of these drugs been given parenterally. For example, the pharmacokinetic interactions between fluconazole and oral midazolam [31], and fluconazole and oral cyclosporine $\mathrm{A}$ or tacrolismus [32], were stronger when both the CYP inhibitor and the substrate (victim) drug were taken orally as compared with the intravenous route of inhibitor administration. Similarly, if the substrate drug (e.g. midazolam) has a significant firstpass metabolism, its intravenous administration can reduce the extent of interaction with orally administered CYP inhibitors (e.g. erythromycin) [29]. However, further studies are needed on the significance of the route of administration for the metabolic interactions of oxycodone.

The interindividual variation in the extent of voriconazole-oxycodone interaction was considerable. In one of our study subjects the AUC of oxycodone was increased more than six-fold. Considering the relatively narrow therapeutic range of oxycodone, a six-fold increase in plasma oxycodone concentration may cause serious adverse effects when increased plasma concentrations occur unexpectedly. In the present study, all cases of nausea or vomiting after oxycodone dosing occurred during the voriconazole phase. It is reasonable to assume that in a patient population using oxycodone, the interindividual variations in the pharmacokinetics and extent of interaction would be even greater than those observed in our study in young, healthy subjects.

Polymorphism of CYP2D6 has been shown to influence the metabolism of several opioid substrates of CYP2D6 such as codeine [33], tramadol [34] and methadone [35]. Genetic alterations in CYP2D6 enzyme activity have also been suggested to influence the pharmacokinetic profile [36] and clinical effects [37-39] of oxycodone. In the present study, one of the subjects was an ultrarapid metabolizer via CYP2D6. Although it is impossible to make conclusions based on one subject, he had distinctly lower oxycodone concentrations than the rest of the group. Consistent with the UM phenotype, his oxycodone metab- 
olism produced much more oxymorphone and noroxymorphone than the others. However, as evidenced by the parallel course of the lines connecting the values for $\mathrm{AUC}_{\mathrm{m}} / \mathrm{AUC}_{\mathrm{p}}$ ratios during the placebo and voriconazole phases in Fig. 2, the magnitude of the voriconazoleoxycodone interaction was similar in the subject with UM phenotype and the others.

Previous studies have indicated that oxycodone metabolites do not significantly contribute to the behavioural effects of oxycodone $[3,9]$. In the present study, there was a linear correlation between the oxycodone plasma concentration and pharmacological response, except for analgesia in the heat-pain test. The analgesic effect of oxycodone was not influenced by voriconazole. This probably reflects the high interindividual variability in opioid sensitivity [40], gender differences in opioid responses [41] or the relatively small dose of oxycodone used in the study. Small differences in drug concentrations do not necessarily affect drug responses because of the log-linear relationship between the drug concentration and effect.

Several opioids such as morphine and methadone are substrates for the efflux transporter P-glycoprotein [42, 43]. Theoretically, voriconazole could inhibit the P-glycoprotein function in the intestinal wall, increasing the oral bioavailability of oxycodone. Similarly, an inhibition of P-glycoprotein at the blood-brain barrier could increase the penetration of oxycodone into the brain. However, the present pharmacodynamic results do not support this possibility, and are in agreement with the results of an animal study, in which the potent P-glycoprotein inhibitor PSC833 did not increase the brain concentrations of oxycodone [44].

In conclusion, voriconazole strongly inhibits the CYP3A-mediated N-demethylation of oxycodone, producing a profound increase in exposure to oral oxycodone. This increase is reflected as a modest change in the behavioural effects of oxycodone. Clinically, lower doses of oxycodone may be needed during voriconazole treatment to avoid opioid-related adverse effects especially after repeated dosing.

Acknowledgements We thank Mrs. Elina Kahra for technical assistance and Professor Antti Pertovaara for the use of the TSA-2. The study was supported by the EVO grant 13821 of the Hospital District of Southwest Finland. All experiments comply with the current laws in Finland, where the research was performed. There are no conflicts of interest.

\section{References}

1. Pöyhiä R, Seppälä T, Olkkola KT, Kalso E (1992) The pharmacokinetics and metabolism of oxycodone after intramuscular and oral administration to healthy subjects. Br J Clin Pharmacol 33:617-621
2. Lalovic B, Phillipis B, Risler LL et al (2004) Quantitative contribution of CYP2D6 and CYP3A to oxycodone metabolism in human liver and intestinal microsomes. Drug Metab Disp 32:447-454

3. Lalovic B, Kharasch E, Hoffer C et al (2006) Pharmacokinetics and pharmacodynamics of oral oxycodone in healthy human subjects: role of circulating active metabolites. Clin Pharmacol Ther 79:461-479

4. Purkins L, Wood N, Ghahramani P et al (2002) Pharmacokinetics and safety of voriconazole following intravenous- to oral-dose escalation regimens. Antimicrob Agents Chemother 46:2546-53

5. Hyland R, Jones BC, Smith DA (2003) Identification of the cytochrome P450 enzymes involved in the N-oxidation of voriconazole. Drug Metab Dispos 31:540-7

6. Murayama N, Imai N, Nakane T et al (2008) Roles of CYP3A4 and CYP2C19 in methyl hydroxylated and $N$-oxidized metabolite formation from voriconazole, a new anti-fungal agent, in human liver microsomes. Biochem Pharmacol 73:2020-2026

7. Niwa T, Shiraga T, Takagi A (2005) Effect of antifungal drugs on cytochrome P450 (CYP) 2C9, CYP2C19, and CYP3A4 activities in human liver microsomes. Biol Pharm Bull 28:1805-1808

8. Niwa T, Inoue-Yamamoto S, Shigara T, Takagi A (2005) Effect of antifungal drugs on cytochrome P450 (CYP) 1A2, CYP2D6, and CYP2E1 activities in human liver microsomes. Biol Pharm Bull 28:1813-1816

9. Heiskanen T, Olkkola KT, Kalso E (1998) Effects of blocking CYP2D6 on the pharmacokinetics and pharmacodynamics of oxycodone. Clin Pharmacol Ther 64:603-611

10. Curry SC, Watts DJ, Katz KD et al (2007) The effect of singledose tramadol on oxycodone clearance. J Emerg Med 33:407-411

11. Samer C, Daali Y, Rebsamen M et al (2005) Determinant role of CYP2D6 and CYP3A4 pathways on the antinociceptive effects of oxycodone. Clin Pharmacol Ther 79:P57-P57

12. Lee H-K, Lewis LD, Tsongalis GJ et al (2006) Negative urine screening caused by rifampicin-mediated induction of oxycodone hepatic metabolism. Clin Chim Acta 267:196-200

13. Michna E, Ross EL, Hynes WL et al (2004) Predicting aberrant drug behavior in patients treated for chronic pain. J Pain Symptom Manage 28:250-258

14. Gage R, Stopher DA (1998) A rapid HPLC assay for voriconazole in human plasma. J Pharm Biomed Anal 17:1449-1453

15. Pennick GJ, Clark M, Sutton DA, Rinaldi MG (2003) Development and validation of HPLC assay for voriconazole. Antimicrob Agents Chemother 7:2348-2350

16. Neuvonen M, Neuvonen PJ (2008) Determination of oxycodone, noroxycodone, oxymorphone and noroxymorphone in human plasma by liquid chromatography-electrospray-tandem mass spectrometry. Ther Drug Monit 30:333-430

17. Sistonen J (2005) CYP2D6 genotyping by a multiplex primer extension reaction. Clin Chem 51:1291-1295

18. Bond A, Lader M (1974) The use of analogue visual scales in rating subjective feelings. Br J Med Psychol 47:211-218

19. Hannington-Kiff JG (1970) Measurements of recovery from outpatient general anaesthesia with a simple ocular test. BMJ 3:132-135

20. Stone BM (1984) Pencil and paper tests: sensitivity to psychotropic drugs. Br J Clin Pharmacol 18:15S-20S

21. Cogan DG (1941) Simplified entoptic pupillometer. Am J Ophthalmol 24:1431-1433

22. Wolff BB, Kantor TG, Jarvik ME, Laska E (1966) Response of experimental pain to analgesic drugs. 1. Morphine, aspirin, and placebo. Clin Pharmacol Ther 7:224-38

23. Saari TI, Laine K, Leino K et al (2006) Effect of voriconazole on the pharmacokinetics of oral and intravenous midazolam. Clin Pharmacol Ther 79:362-370

24. Saari TI, Laine K, Leino K et al (2007) Effect of voriconazole on the pharmacokinetics and pharmacodynamics of zolpidem in healthy subjects. Br J Clin Pharmacol 63:116-120 
25. Saari TI, Laine K, Bertilsson L et al (2007) Voriconazole and fluconazole increase the exposure to oral diazepam. Eur J Clin Pharmacol 63:941-949

26. Saari TI, Laine K, Leino K et al (2006) Voriconazole, but not terbinafine, markedly reduces alfentanil clearance and prolongs its half-life. Clin Pharmacol Ther 80:502-8

27. Saari TI, Laine K, Neuvonen M et al (2008) Effect of voriconazole and fluconazole on the pharmacokinetics of intravenous fentanyl. Eur J Clin Pharmacol 64:25-30

28. Liu P, Foster G, LaBadie R et al (2007) Pharmacokinetic interaction between voriconazole and methadone at steady state in patients on methadone therapy. Antimicrob Agents Chemother $51: 110-118$

29. Olkkola KT, Aranko K, Luurila H et al (1993) A potentially hazardous interaction between erythromycin and midazolam. Clin Pharmacol Ther 53:298-305

30. Olkkola KT, Ahonen J, Neuvonen PJ (1996) The effect of the systemic antimycotics, itraconazole and fluconazole, on the pharmacokinetics and pharmacodynamics of intravenous and oral midazolam. Anesth Analg 82:511-516

31. Ahonen J, Olkkola KT, Neuvonen PJ (1997) Effect of route of administration of fluconazole on the interaction between fluconazole and midazolam. Eur J Clin Pharmacol 51:415-419

32. Mihara A, Mori T, Aisa Y et al (2008) Greater impact of oral fluconazole on drug interaction with intravenous calcineurin inhibitors as compared with intravenous fluconazole. Eur J Clin Pharmacol 64:89-91

33. Poulsen L, Brøsen K, Arendt-Nielsen L et al (1996) Codeine and morphine in extensive and poor metabolizers of sparteine: pharmacokinetics, analgesic effect and side effects. Eur J Clin Pharmacol 51:289-295

34. Paar WD, Poche S, Gerloff J, Dengler HJ (1997) Polymorphic CYP2D6 mediates O-demethylation of the opioid analgesic tramadol. Eur J Clin Pharmacol 53:235-239
35. Eap CB, Broly F, Mino A et al (2001) Cytochrome P450 2D6 genotype and methadone steady-state concentrations. J Clin Psychopharmacol 21:229-234

36. Liukas A, Kuusniemi K, Aantaa R et al (2008) Plasma concentrations of oral oxycodone are greatly increased in the elderly. Clin Pharmacol Ther (epub ahead of print). doi:10.1038/clpt.2008.64

37. de Leon J, Dinsmore L, Wedlund P (2003) Adverse drug reactions to oxycodone and hydrocodone in CYP2D6 ultrarapid metabolizers. J Clin Psychopharm 23:420-421

38. Susce MT, Murray-Carmichael E, de Leon J (2006) Response to hydrocodone, codeine and oxycodone in a CYP2D6 poor metabolizer. Prog Neuropsychopharmacol Biol Psychiatry 30:1356-1358

39. Foster A, Mobley E, Wang Z (2007) Complicated pain management in a CYP2D6 poor metabolizer. Pain Pract 7:352-356

40. Koltzenburg M, Pokorny R, Gasser UE, Richarz U (2006) Differential sensitivity of three experimental pain models in detecting the analgesic effects of transdermal fentanyl and buprenorphine. Pain 126:165-174

41. Sarton E, Olofsen E, Romberg R et al (2000) Sex differences in morphine analgesia: an experimental study in healthy volunteers. Anesthesiol 93:1245-1254

42. Thompson SJ, Koszdin K, Bernards CM (2000) Opiate-induced analgesia is increased and prolonged in mice lacking P-glycoprotein. Anesthesiol 92:1392-9

43. Wang JS, Ruan Y, Taylor RM et al (2004) Brain penetration of methadone (R)- and (S)-enantiomers is greatly increased by P-glycoprotein deficiency in the blood-brain barrier of Abcbla gene knockout mice. Psychopharmacology (Berl) 173:132-138

44. Boström E, Simonsson US, Hammarlund-Udenaes M (2005) Oxycodone pharmacokinetics and pharmacodynamics in the rat in the presence of the P-glycoprotein inhibitor PSC833. J Pharm Sci 94:1060-1066 